\section{$\mathbf{R}_{\text {ESEA }}^{\text {RTICLE }}$}

\title{
Specific antibacterial activity of bifidobacteria
}

\author{
RITA NARAYANAN AND B. SURESH SUBRAMONIAN ${ }^{1}$
}

Members of the Research Forum Associate Author :

${ }^{1}$ Department of Dairy Science, Madras Veterinary College, CHENNAI (T.N.) INDIA

AUTHOR FOR CORRESPONDENCE : RITA NARAYANAN

Department of Dairy Science, Madras Veterinary College, CHENNAI (T.N.) INDIA
Abstract : Dairy organisms like Bifidobacteria and Lactobacillus are gaining importance as probiotic organisms. They are increasingly used in food as functional foods to improve nutritional benefits. Recently much emphasis is also laid for isolating these organisms from indigenous sources. Hence an attempt is made in his paper to isolate bifidobacterium group of organisms from breast fed infant faeces and study their antimicrobial property.

Key words : Dairy organisms, Bifidobacteria, Antimicrobial property

How to cite this paper : Narayanan, Rita and Subramonian, B. Suresh (2016). Specific antibacterial activity of bifidobacteria Vet. Sci. Res. J., 7(2) : 74-78, DOI : 10.15740/HAS/VSRJ/7.2/74-78.

Paper History : Received : 27.06.2016; Revised : 15.08.2016; Accepted : 01.09.2016 